\title{
PERAN BIMBINGAN BELAJAR ORANG TUA TERHADAP DISIPLIN BELAJAR SISWA
}

\author{
Bella Elvira $^{a)}$, Elly Sukmanasa ${ }^{\left.a^{*}\right)}$, Tatang Muhajang ${ }^{a)}$ \\ a) Universitas Pakuan, Bogor, Indonesia \\ ${ }^{*}$ e-mail korespondensi : sukmanasaelly@gmail.com
}

Riwayat Artikel : diterima: 20 Juli 2019; direvisi: 26 Juli 2019; disetujui: 26 Agustus 2019

\begin{abstract}
Abstrak. Tujuan dari penelitian ini adalah untuk mengetahui pengaruh bimbingan belajar orang tua terhadap disiplin belajar siswa. Data penelitian ini diperoleh dengan menggunakan instrument angket untuk kedua variable. Uji validitas instrumen interaksi sosial dan disiplin dihitung menggunakan rumus Koefisien Korelasi Product Moment Pearson dan untuk koefisien reliabilitas dihitung menggunakan rumus Alpha Cronbach. Populasi dalam penelitian ini adalah siswa kelas IV Sekolah Dasar Negeri Cibeureum 4 Kota Bogor yang berjumlah 89 siswa. Sampel yang diambil 47 siswa yang diperoleh menggunakan rumus Taro Yamane. Pengujian prasyarat analisis berupa uji normalitas (Liliefors). Setelah dari uji normalitas kemudian dilakukan pengujian homogenitas (Fisher). Data yang sudah dinyatakan normal dan homogen digunakan untuk menguji hipotesis yang hasilnya menunjukan terdapat pengaruh bimbingan belajar orang tua terhadap disiplin belajar siswa. Teknik analisis regresi korelasi sederhana menghasilkan suatu model hubungan yang dinyatakan dalam bentuk persamaan regresi yaitu $\hat{Y}=9,99+0,86 \mathrm{X}$, dengan harga thitung sebesar 17 lebih besar dari ttabel dengan taraf nyata 0,05 sebesar 2,021 dan konstribusi berdasarkan hasil penelitian sebesar $86 \%$. Berdasarkan hasil penelitian di atas, maka dapat disimpulkan bahwa terdapat pengaruh bimbingan belajar orang tua terhadap disiplin belajar siswa kelas IV di Sekolah Dasar Negeri Cibeureum 4 Kota Bogor tahun pelajaran 2018/2019.
\end{abstract}

Kata Kunci: disiplin belajar, bimbingan belajar orang tua

\section{THE EFFECT OF PARENTAL TUTORING ON STUDENT DISCIPLINE}

Abstract. The purpose of this study was to determine the effect of parental tutoring on student learning discipline. The data of this study were obtained using a questionnaire instrument for both variables. The validity test of the instrument of social interaction and discipline is calculated using the Pearson Product Moment Correlation Coefficient formula and the reliability coefficient is calculated using the Cronbach Alpha formula. The population in this study were the fifth grade students of Cibeureum 4 Public Elementary School in Bogor City, amounting to 89 students. The samples taken by 47 students were obtained using the Taro Yamane formula. Tests for analysis prerequisites in the form of a normality test (Liliefors). After the normality test, homogeneity (Fisher) was tested. Data that has been declared normal and homogeneous is used to test the hypothesis, the results of which show that there is an influence of parents' tutoring on student learning discipline. Simple correlation regression analysis technique produces a relationship model which is expressed in the form of a regression equation that is $\hat{Y}=9.99+0.86 \mathrm{X}$, with a tcount of 17 greater than t table with a real level of 0.05 of 2.021 and a contribution based on research results of $86 \%$. Based on the results of the above research, it can be concluded that there is an influence of parents' tutoring on the discipline of learning in grade IV students at Cibeureum 4 Elementary School in Bogor City 2018/2019.

Keywords: tutoring parents, student learning discipline.

\section{PENDAHULUAN}

Pendidikan adalah faktor yang paling penting dan prioritas utama yang membutuh-kan perhatian serius dari semua pihak, karena pendidikan adalah penentu kemajuan bangsa di masa depan [1]. Tujuan dan cita-cita nasional, untuk kehidupan intelektual bangsa terkandung dalam UUD 1945. Pemerintah bersama masyarakat terus mencari pengembangan pendidikan demi terwujudnya bangsa yang mandiri, unggul dan siap menghadapi dunia globalisasi [2]. Berdasarkan UU No. 20 Tahun 2003 tentang Sistem Pendidikan Nasional, dijelaskan bahwa pendidikan merupakan usaha sadar dan terencana untuk mewujudkan suasana belajar dan proses pembelajaran, agar peserta didik secara aktif mengembangkan potensi dirinya untuk memiliki kekuatan spiritual keagamaan, pengendalian diri, kepribadian, kecerdasan, akhlak mulia, serta keterampilan yang diperlukan dirinya, masyarakat, bangsa dan negara.
Kurikulum 2013 memfokuskan kepada pendidikan karakter siswa bahwa disipin belajar sangatlah penting sebagai suatu faktor dari keberhasilan siswa dalam mencapai tujuan pembelajaran yang telah ditetapkan oleh Kemendikbud. disiplin merupakan salah satu karakter yang penting untuk ditanamkan pada diri siswa sejak kecil. Suchyadi mengungkapkan bahwa perbedaan karakter anak dengan kebutuhan yang beragam akan membutuhkan kemampuan guru untuk menggabungkan berbagai kemampuan dan bakat masing-masing anak [3]. Salah satunya dalam kegiatan belajar mengajar. disiplin belajar di sekolah dapat dilihat dari ketertiban siswa dalam menaati tata tertib sekolah diantaranya masuk dan pulang sekolah tepat waktu, mengerjakan tugas tepat waktu, mengenakan seragam sesuai jadwal dan sebagainya. Faktor-faktor yang mempengaruhi disiplin belajar yaitu faktor intrinsik dan faktor ekstrinsik. Faktor yang pertama yaitu faktor instrinsik, meliputi faktor psikologi, seperti minat, motivasi, bakat, konsentrasi, dan 
kemampuan kognitif. Faktor fisiologis, yang termasuk dalam faktor fisiologis antara lain pendengaran, penglihatan, kesegaran jasmani, kekurangan gizi, kurang tidur dan sakit yang diderita. Faktor yang kedua yaitu faktor ekstrinsik meliputi faktor non-sosial, seperti keadaan udara, waktu, tempat dan peralatan maupun media yang dipakai untuk belajar. Faktor sosial, terdiri atas lingkungan keluarga, lingkungan sekolah, dan lingkungan masyarakat. mengenai faktor-faktor yang mempengaruhi proses belajar dan disiplin belajar, artinya faktor-faktor tersebut selain mempengaruhi disiplin belajar siswa, masing-masing faktorpun saling berhubungan satu sama lain. Pola asuh orang tua merupakan cara dan kebiasaan yang dilakukan orang tua dan dirasakan oleh anak, sehingga pola tersebut tentu akan berbeda pada setiap orang tua. Pola asuh yang diterapkan orang tua yang memiliki anak normal pun dapat menjadi alasan pola asuh yang berbeda. Jika anak pada usia 6-12 tahun, biasanya orang tua yang memiliki anak normal masih bisa memberikan pola asuh yang membebaskan dan membiarkan [4].

Penelitian Mulyaningsih [5] menunjukan bahwa terdapat pengaruh yang positif dan signifikan antara bimbingan belajar orang tua terhadap perilaku disiplin pada seluruh siswa kelas V SD se-Gugus Diponogoro Bansari Temanggung sebanyak 103 siswa dibuktikan dengan hasil uji regensi $\mathrm{X}$ terhadap $\mathrm{Y}$ dan ditunjukkan pada koefisien determinasi diperoleh nilai $\mathrm{R}$ square sebesar $21,9 \%$. Dan berdasarkan uji korelasi sederhana terdapat hubungan yang kuat karena menunjukkan nilai hubungan sebesar 0,693.

Berdasarkan penelitian diatas banyak sekali yang mempengaruhi disiplin belajar, salah satu yang mempengaruhinya adalah lingkungan keluarga siswa. Lingkungan keluarga salah satunya meliputi bimbingan belajar siswa. Tingkat kedisiplinan siswa di Sekolah Dasar Cibereum 4 secara umum masih rendah, baik disiplin waktu maupun disiplin sikap, siswa yang memiliki sikap disiplin rendah masih sangat butuh bimbingan dikarenakan banyaknya siswa yang masih telat datang kesekolah maupun tidak mengerjakan tugas dirumahnya

Untuk mengatasi masalah tersebut harus ada kerjasama antara guru dan orang tua siswa agar bisa meningkatkan disiplin belajarnya. Untuk membantu siswa meningkatkan disiplin belajar, maka perlu dilakukan penelitian mengenai pengaruh bimbingan belajar orang tua dengan disiplin belajar siswa di sekolah dasar.

Menurut Rosma [6] disiplin adalah kepatuhan menaati peraturan dan ketentuan yang telah ditetapkan lalu menurut Khafid [7] berpendapat Disiplin belajar merupakan salah satu sikap atau perilaku yang harus dimiliki oleh siswa Diperkuat menurut Al Fath [8] mengemukakan bahwa disiplin belajar merupakan pernyataan sikap dan perbuatan siswa dalam melaksanakan kewajiban belajar secara sadar dengan cara menaati peraturan yang ada dilingkungan sekolah maupun dilingkungan rumah.

Selanjutnya menurut Ardiansyah [9] Disiplin belajar merupakan salah satu sikap atau perilaku yang harus dimiliki oleh siswa, menurut Huda [10] disiplin merupakan salah satu unsur yang penting dalam proses pembelajaran baik sebelum, selama dan setelah proses pembelajaran di kelas.

Berdasarkan uraian di atas penelitian di atas dapat disintesiskan bahwa disiplin belajar adalah suatu kegiatan atau perilaku sosial seseorang dalam melaksanakan tata tertib yang berlaku atau patuh pada aturan yang berlaku dalam proses belajar. Menurut Andayani [11] bimbingan belajar adalah bimbingan yang diberikan oleh orang yang ahli, baik itu individu maupun kelompok yang mengalami masalah yang dihadapi dalam belajar sehingga setelah melalui proses perubahan dalam belajar mereka dapat mencapai hasil belajar yang optimal. Menurut Miftahillah [12] menyatakan bahwa bimbingan merupakan suatu proses membantu individu, dengan menggunakan kata membantu berarti dalam kegiatan bimbingan tidak ada unsur paksaan. Selanjutnya Yusra [13] Bimbingan belajar merupakan upaya pemberian bantuan yang diberikan guru bimbingan dan konseling kepada siswa dalam menghadapi dan memecahkan masalah - masalah belajar. Diperkuat oleh Mulyaningsih [5] bimbingan belajar orang tua dapat diartikan sebagai proses bantuan yang diberikan oleh orang tua kepada anak ketika mendapatkan kesulitan dalam kegiatan belajar. Lalu menurut pendapat Suherman [14] bimbingan belajar adalah suatu proses pemberian bantuan dari guru/guru pembimbing kepada siswa dengan cara mengembangkan suasana belajar yang kondusif dan menumbuhkan kemampuan agar siswa terhindar dari dan atau dapat mengatasi kesulitan belajar yang mungkin dihadapinya sehingga mencapai hasil belajar

Cara orang tua mendidik dan membimbing anaknya dapat mempengaruhi disiplin belajar anaknya, orang tua sebagai pembimbing pertama dan utama mampu mengarahkan dan membimbing kesulitan belajar yang dialami anak. Hal ini dinyatakan oleh Zainuren [15] bahwa peranan orang tua adalah pola tingkah laku dari ayah dan ibu berupa tanggung jawab untuk mendidik, mengasuh dan membimbing anak-anaknya untuk mencapai tahapan tertentu yang menghantarkan anak untuk siap dalam kehidupan bermasyarakat. Diperkuat dengan pendapat Wiartha [16] peranan orang tua dalam keluarga mempunyai peranan besar dalam pembangunan masyarakat.

Dalam rangka pelaksanaan pendidikan nasional, peranan orang tua semakin jelas dan penting terutama dalam penanaman sikap dan nilai atau norma norma hidup bertetangga dan bermasyarakat, pengembangan bakat dan minat serta pembinaan bakat dan kepribadian.

Diperjelas juga oleh Novrinda [17] peran orangtua adalah perilaku yang yang berkenaan dengan orangtua dalam memegang posisi tertentu dalam lembaga keluarga yang di dalamnya berfungsi sebagai pengasuh, pembimbing dan pendidik bagi anak. Berdasarkan penelitian di atas dapat disintesiskan bahwa bimbingan belajar orang tua adalah proses bantuan yang diberikan oleh orang tua dalam belajar kepada anaknya agar dapat menjadi pribadi yang mandiri, pribadi yang mengatasi dan menyelesaikan berbagai permasalahan yang dihadapi dalam kegiatan belajar. 


\section{METODE PENELITIAN}

Penelitian dilaksanakan dengan pendekatan kausalitas melalui rancangan penelitian. Penelitian korelasi ini dilaksanakan pada siswa kelas IV di Sekolah Dasar Negeri Cibereum 4 Kota Bogor. Penelitian kausal ini dilaksanakan pada semester genap tahun ajaran 2018/2019, penentuan waktu penelitian mengacu pada kalender akademik sekolah. Penelitian yang bertujuan untuk mengetahui tentang pengaruh antara dua variabel, yaitu variabel bebas $(X)$ dalam penelitian ini adalah Bimbingan belajar orang tua dan variabel terikat $(\mathrm{Y})$ yaitu disiplin belajar siswa.

Teknik pengumpulan data penelitian ini menggunakan metode survei untuk mengumpulkan data dari siswa yang terpilih sebagai responden untuk memperoleh informasi mengenai hubungan antara bimbingan belajar orang tua dengan disiplin belajar siswa kelas IV di Sekolah Dasar Negeri Cibereum 4 Kota Bogor. Metode untuk instrument bimbingan belajar orang tua dan disiplin belajar siswa menggunakan angket (kuesioner) sebanyak 40 butir soal instrumen uji coba Instrumen disusun dalam bentuk pernyataan dengan menggunakan 5 rentang skala likert. Metode penelitian yang digunakan adalah metode penelitian survei dengan teknik korelasional. Teknik pengumpulan data menggunakan agket berupa pernyataan dengan 5 alternatif jawaban.

\section{HASIL DAN PEMBAHASAN}

Deskripsi data penelitian ini dikelompokkan menjadi dua bagian, yaitu terdiri dari kelompok data variabel terikat yaitu, Disiplin belajar siswa (Y), dan data variabel bebas, bimbingan belajar orang tua $(\mathrm{X})$ yang dideskripsikan dalam bentuk deskriptif statistik. Deskripsi data masing-masing yaitu skor terendah, skor tertinggi, rentang skor, rata-rata (mean), nilai tengah (median), nilai yang sering muncul (modus), standar deviasi (SD), varians sampel, dan total skor.

Tabel 1. Uji Homogenitas Hasil Bimbingan Belajar Orang Tua dan Disiplin Belajar siswa

\begin{tabular}{|c|c|c|c|c|c|}
\hline No & $\begin{array}{c}\text { Varian yang } \\
\text { diuji }\end{array}$ & $\begin{array}{c}\text { Jumlah } \\
\text { Sampe }\end{array}$ & Fhitung & Ftabel & Simpulan \\
\hline 1 & $\mathrm{X}$ atas Y & 47 & 1,07 & 4,06 & Homogen \\
\hline
\end{tabular}

Berdasarkan hasil perhitungan uji homogenitas variabel bimbingan belajar orang tua $(\mathrm{X})$ dan disiplin belajar Siswa $(\mathrm{Y})$ diperoleh Fhitung sebesar 1,07 untuk sampel 47 dan taraf $\alpha(0,05)$ diperoleh $F_{\text {tabel }}$ 4,06. Dimana jika Fhitung $<F_{\text {tabel }}$ berarti homogen. Sesuai dengan hasil perhitungan analisis persamaan regresi pada gambar diagrgam pancar diatas menunjukan suatu korelasi bahwa terdapat hubungan positif dan menunjukan keeratan antara kedua variabel dengan ketentuan korelasi positif variabel $\mathrm{Y}$ akan naik jika variabel $\mathrm{X}$ naik, Jika variabel $\mathrm{X}$ dekendalikan maka variabel $\mathrm{Y}$ juga akan dikendalikan. Kebenaran dari hasil regresi di atas digunakan untuk menguji hipotesis mengenai ada tidaknya hubungan positif antara pola asuh orang tua dengan disiplin belajar(Y). Pengaruh fungsional antara X dan Y di sajikan dalam bentuk $\hat{\mathrm{Y}}=(9,99+0,86)$ dengan $\mathrm{X}$ adalah signifikan.

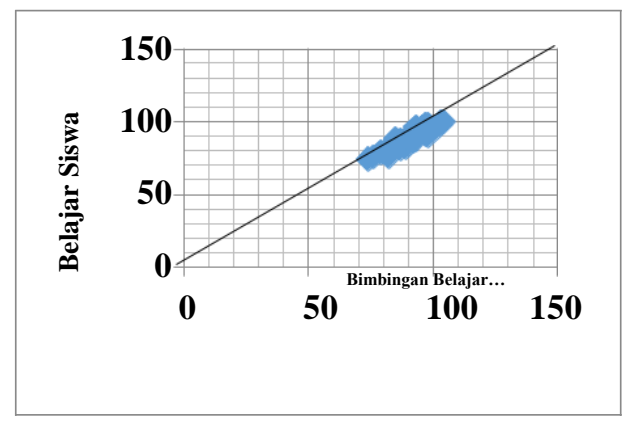

Gambar 1. Diagram Pancar Hubungan Fungsional Variabel Bimbingan Belajar Orang Tua (X) dan Disiplin Belajar Siswa (Y)

Hasil analisis Product Moment menunjukan koefisien korelasi 0,93 . Hal ini menunjukan adanya korelasi yang sangat tinggi antara bimbingan belajar orang tua dengan disiplin belajar siswa dan arahnya yang positif. Artinya jika bimbingan belajar orang tua tinggi maka disiplin belajar siswa pun akan ikut tinggi dan sebaliknya. Pengaruh antara bimbingan orang tua dengan disiplin belajar siswa sebesar $96 \%$.

Berdasarkan hasil uji signifikan koefisien korelasi diperoleh hasil uji keberartian koefisien korelasi yaitu, penguji hipotesis menggunakan uji korelasi Product Momen Pearson. Hasil analisis menunjukan pengaruh positif bimbingan belajar orang tua dengan disiplin belajar siswa dengan persamaan $\hat{Y}=9,99+0,86 \mathrm{x}$. Selanjutnya hasil uji signifikasi koefisien korelasi diperoleh thitung $=16,84$ sedangkan tabel 2,021 dan dk 45. Sehingga thitung $>$ tabel yaitu $16,84>2,021$.

Perbandingan kedua nilai yang diperoleh menunjukan bahwa thitung $>$ tabel yang menunjukan bahwa pola asuh orang tua (X) dengan disiplin belajar (Y) signifikan. Karena koefisien korelasi yang diperoleh positif, artinya semakin tinggi bimbingan belajar orang tua semakin tinggi pula disiplin belaja siswa yang diperoleh.

Kekuatan pengaruh antara bimbingan belajar orang tua dengan disiplin belajar siswa ditunjukkan dengan koefisien korelasi sebesar 0,93 Harga koefisien tersebut menunjukan bahwa terdapat hubungan yang sangat kuat antara pola asuh orang tua dengan disiplin belajar. Besarnya kontribusi pola asuh orang tua terhadap disiplin belajar ditunjukkan oleh koefisien $\left(\mathrm{r}^{2}\right)$ sebesar 0,86 dengan koefisien determinasi sebesar $86 \%$. Hal tersebut berarti bahwa penaikan atau penurunan disiplin belajardipengaruhi oleh tingkat bimbingam belajar orang tua $93 \%$. sedangkan sisanya $14 \%$ dipengaruhi oleh faktor-faktor lainnya.

\section{SIMPULAN}

Berdasarkan hasil pengolahan data, hasil hipotesis dan pembahasan hasil penelitian, maka dapat disimpulkan bahwa Bimbingan belajar orang tua demokratis lebih dominan 
diterapkan oleh orang tua siswa di SDN Cibereum 4 dan terdapat pengaruh yang positif antara bimbingan belajar orang tua terhadap disiplin belajar siswa, yang berarti semakin tinggi bimbingan belajar orang tua maka semakin tinggi disiplin belajar siswa. Demikian sebaliknya semakin rendah bimbingan belajar orang tua maka semakin rendah pula disiplin belajar siswa.

\section{REFERENSI}

[1] Y. Suchyadi and Nurjanah, 2018. "Relationship between Principal Supervision in Increasing the Job Satisfaction of Private Junior High School Teachers in East Bogor District," J. Humanit. Soc. Stud., vol. 02, no. 01, pp. 26-29,

[2] Y. Suchyadi, 2017. "Relationship between Work Motivation and Organizational Culture in Enhancing Professional Attitudes of Pakuan University Lecturers," vol. 01, no. 01, 2017.

[3] Y. Suchyadi, Y. Ambarsari, and E. Sukmanasa, 2018. "Analysis of Social Interaction of Mentally Retarded Children," J. Humanit. Soc. Stud., vol. 02, no. 02, pp. 17-21, 2018.

[4] S. Setiarani and Y. Suchyadi, 2018."Pola Asuh Orang Tua Terhadap Anak Tuna Netra Berprestasi," J. Pendidik. Pengajaran Guru Sekol. Dasar, vol. 01, no. 01, pp. 15-18, 2018.

[5] Mulyaningsih.2016. Pengaruh Bimbingan Belajar Orang Tua Terhadap Perilaku Disiplin Dan Hasil Belajar Matematika Siswa Kelas V Sd Se-Gugus Diponegoro Bansari Temanggun. Jurusan Pendidikan Guru Sekolah Dasar. Fakultas Ilmu Pendidikan Universitas Negeri Semarang

[6] Rosma, Elly. Hubungan Kedisiplinan Terhadap Hasil Belajar Siswa Kelas V Di Sd Negeri 10 Banda Aceh Jurnal Pesona Dasar Universitas Syiah Kuala Vol. 3 No.4.

[7] Khafid, Muhammada. 2007. Pengaruh Disiplin Belajar dan Lingkungan Keluarga Terhadap Hasil Belajar Ekonomi. Vol 2, No 2. Jurnal Dinamika Pendidikan. Universitas Negeri Semarang.

[8] Al Fath, A.M. 2015. Pengaruh Motivasi, Lingkungan dan Disiplin terhadap Prestasi Belajar Siswa pada Mata Pelajaran IPA Kelas V SDN 19 Banda Aceh. Jurnal STKIP Bina Bangsa Getsempena, 6 (1), 111.

[9] Ardiansyah, Hanif. 2013. Faktor - Faktor Yang Mempengaruhi Disiplin Belajar Siswa Kelas Xii Jurusan Administrasi Pekantoran Di SMK NU 01 Kendal Tahun Pelajaran 2012/201. Jurusan Pendidikan Ekonomi. Fakultas Ekonomiuniversitas Negeri Semarang.

[10] Huda, Ainil. 2013. Pengaruh Peranan Teman Sebaya, Disiplin Belajar Dan Motivasi Belajar Terhadap Hasil Belajar Ekonomi Siswa Kelas X Di Sma Negeri 1 Lembah Melintang Kabupaten Pasaman Barat. Fakultas Ekonomi. Universitas Negeri Padang.
[11] Andayani, Sri Nonik. 2014. Penerapan Layanan Bimbingan Belajar Untuk Meningkatkan Prestasi Belajar Bagi Siswa Yang Mengalami Kesulitan Belajar Siswa Kelas X4 Sma Negeri 1 Sukasada. Vol 2 No 1

[12] Miftahillah. 2014. Hubungan Antara Bimbingan Belajar Dan Motivasi Belajar Dengan Prestasi Belajar Siswa Di MI Nindhomiyah Jombang. Vol 1 No 2. Modeling: Jurnal Program Studi PGMI

[13] Yusra, Affan. 2017. Model Bimbingan Belajar Berbasis Prinsip-prinsip Belajar dalam Islam untuk Meningkatkan Kemanfaatan Ilmu. Universitas Negeri Semanrang. Indonesia

[14] Suherman, Uman. 2015. Bimbingan Belajar. UPI. EDU. Vol 2

[15] Zainuren, Yunia Rahma Utami 2014 Peranan Orang Tua Terhadap Penanaman Nilai Kejujuran Anak. Vol 1, No 7. Jurnal Kultur Demokrasi

[16] Wiartha, Pantris. 2017. Peran Orang Tua Dalam Menanamkan Nilai - Nilai Agama Islam Di Desa Winong Kalidiwir Tulungagung. Repo.lainTulungagung.ac.id

[17] Novrinda. 2017. Peran Orangtua Dalam Pendidikan Anak Usia Dini Ditinjau Dari Latar Belakang Pendidikan. Jurnal Potensia, PG-PAUD FKIP UNIB, Vol.2 No.1 